ARTICLE

Received 23 Sep 2014 | Accepted 27 Oct 2014 | Published 6 Jan $2015 \quad$ DOl: 10.1038/ncomms6682

\title{
A highly efficient polysulfide mediator for lithium-sulfur batteries
}

Xiao Liang ${ }^{1}$, Connor Hart ${ }^{1}$, Quan Pang ${ }^{1}$, Arnd Garsuch², Thomas Weiss ${ }^{2}$ \& Linda F. Nazar ${ }^{1}$

The lithium-sulfur battery is receiving intense interest because its theoretical energy density exceeds that of lithium-ion batteries at much lower cost, but practical applications are still hindered by capacity decay caused by the polysulfide shuttle. Here we report a strategy to entrap polysulfides in the cathode that relies on a chemical process, whereby a hostmanganese dioxide nanosheets serve as the prototype-reacts with initially formed lithium polysulfides to form surface-bound intermediates. These function as a redox shuttle to catenate and bind 'higher' polysulfides, and convert them on reduction to insoluble lithium sulfide via disproportionation. The sulfur/manganese dioxide nanosheet composite with $75 \mathrm{wt} \%$ sulfur exhibits a reversible capacity of $1,300 \mathrm{~mA} \mathrm{hg}^{-1}$ at moderate rates and a fade rate over 2,000 cycles of $0.036 \% /$ cycle, among the best reported to date. We furthermore show that this mechanism extends to graphene oxide and suggest it can be employed more widely.

\footnotetext{
${ }^{1}$ Department of Chemistry, University of Waterloo, 200 University Avenue West, Waterloo, Ontario, Canada N2L 3G1. ${ }^{2}$ BASF SE, 67056 Ludwigshafen, Germany. Correspondence and requests for materials should be addressed to L.F.N. (email: Ifnazar@uwaterloo.ca).
} 
A $s$ the development of portable electronics devices, electric vehicles and large-scale energy storage increases, so do the demands for energy storage batteries with high energy density and long service life. At the same time, it is recognized that traditional lithium-ion batteries are approaching their theoretical energy density limits ${ }^{1-4}$. Lithium-sulfur batteries are one of the most promising candidates to satisfy emerging market demands ${ }^{5-7}$, as they possess a theoretical capacity and energy density of $1,675 \mathrm{~mA} \mathrm{hg}^{-1}$ and $2,500 \mathrm{~kW} \mathrm{~kg}^{-1}$, respectively, superior to current lithium-ion batteries ${ }^{8,9}$. In addition, they present an inherently low competitive cost due to the high natural abundance of sulfur. These advantages suggest that the lithiumsulfur battery should be capable of energy storage several times greater than conventional lithium-ion batteries, with reduced cost. However, practical applications are currently hindered by several obstacles. These predominantly relate to the insulating nature of sulfur and lithium sulfides, which require addition of conductive additives (hence lowering the active sulfur mass fraction), pronounced capacity fading on cycling and an internal redox shuttle that lowers Coulombic efficiency ${ }^{0}$. Over decades, much effort has been expended to try to solve these problems by trapping the polysulfides within the cathode structure. The most popular approaches are to encapsulate sulfur in the pores of carbon materials or a conductive polymer matrix. Meso/ microporous carbons ${ }^{11-14}$, carbon spheres $^{15-17}$, carbon nanotubes/fibres ${ }^{18-20}$, polyaniline ${ }^{21}$, polypyrrole $^{22,23}$ and poly(3,4-ethylenedioxythiophene $)^{24}$ sulfur-host cathodes have all had a positive effect on increasing the cycle life of lithiumsulfur cells. However, such architectures and polymer coatings can only partially retain polysulfides and are limited in their function over time, owing to structural changes that arise from the $80 \%$ volume change of the sulfur cathode on discharge. Twodimensional materials such as graphene oxides (GOs) have also been very successfully employed as cathode hosts to increase the performance of the lithium-sulfur battery, where interaction between the oxygen/nitrogen functional groups and sulfur/ polysulfides has been suggested ${ }^{25-28}$. Similarly, binding polysulfides onto hydrophilic metal oxide hosts was shown to significantly aid in maintaining high-capacity retention ${ }^{29-31}$. More recently, high-surface-area polar metallic oxides have been used as a two-in-one approach to provide both a 'sulfiphilic' surface and supply electron transport to effect surface-enhanced redox chemistry ${ }^{32}$; or to spatially locate $\mathrm{Li}_{2} \mathrm{~S}$ deposition and enhance redox ${ }^{33}$. Organometallic redox mediators are shown to provide better utilization of $\mathrm{Li}_{2} \mathrm{~S}$ (ref. 34). Additives such as $\mathrm{P}_{2} \mathrm{~S}_{5}$ also effectively control $\mathrm{Li}_{2} \mathrm{~S}$ deposition and aid in elimination of the polysulfide shuttle ${ }^{35}$.

Herein, we present a quite different chemical approach to polysulfide retention in the sulfur cathode, which relies on mediating polysulfide redox through insoluble thiosulfate species in a two-step process. The thiosulfate groups are first created in situ by oxidation of initially formed soluble lithium polysulfide (LiPS) species on the surface of ultra-thin $\mathrm{MnO}_{2}$ nanosheets. As reduction proceeds, the surface thiosulfate groups are proposed to anchor newly formed soluble 'higher' polysulfides by catenating them to form polythionates and converting them to insoluble 'lower' polysulfides. The polythionate complex formed on the surface is thus best described as a transfer mediator. This process curtails active mass loss during the discharge/charge process and supresses the polysulfide shuttle to result in high-performance cathodes with high sulfur loading, capable of high-capacity retention of $92 \%$ after 200 cycles at a C/5 rate and cycling over 2,000 cycles at $2 \mathrm{C}$ with a capacity decay of $0.036 \%$ per cycle.

\section{Results}

Synthesis and characterization. The $\mathrm{MnO}_{2}$ nanosheets were prepared by reducing $\mathrm{GO}$ with $\mathrm{KMnO}_{4}$ (ref. 36). Transmission electron microscopy (TEM) and scanning electron microscopy (SEM) images (Fig. 1a,b) reveal their two-dimensional lamellar structure. The selected area electron diffraction pattern of the $\mathrm{MnO}_{2}$ nanosheets shows weak diffraction rings characteristic of $\delta-\mathrm{MnO}_{2}$, and the high-resolution TEM image in Fig. 1c exhibits a 0.25 -nm lattice spacing corresponding to the (100) planes. X-ray diffraction (Fig. 1d) analysis confirms the $\mathrm{MnO}_{2}$ nanosheets are monoclinic birnessite, $\delta-\mathrm{MnO}_{2}$ (JCPDS-01-080-1098). Birnessite is a phyllomanganate, a manganese oxide containing predominantly $\mathrm{Mn}^{4+}$ cations assembled in layers of edge-sharing octahedra. A layer charge deficit arises from the presence of $\mathrm{Mn}^{3+}$ cations and/or vacant-layer octahedra and is compensated by the presence of interlayer cations, which are hydrolysable $\mathrm{K}^{+}$in this case. Water molecules are also present between the a
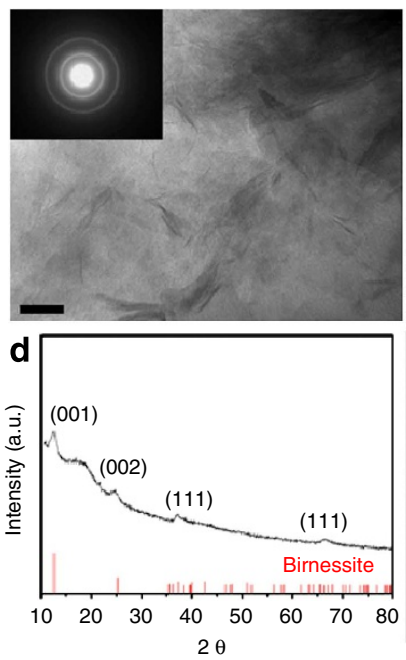

b
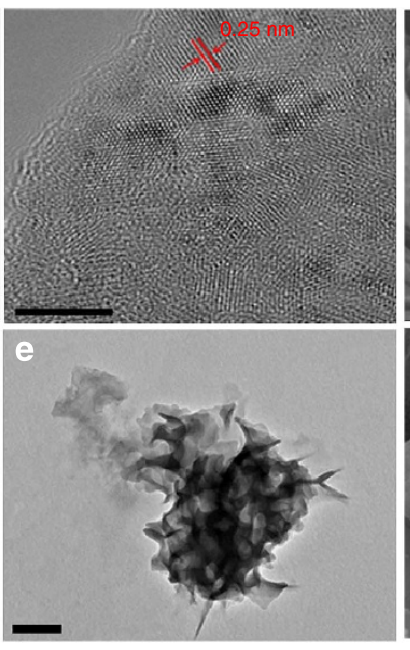

C
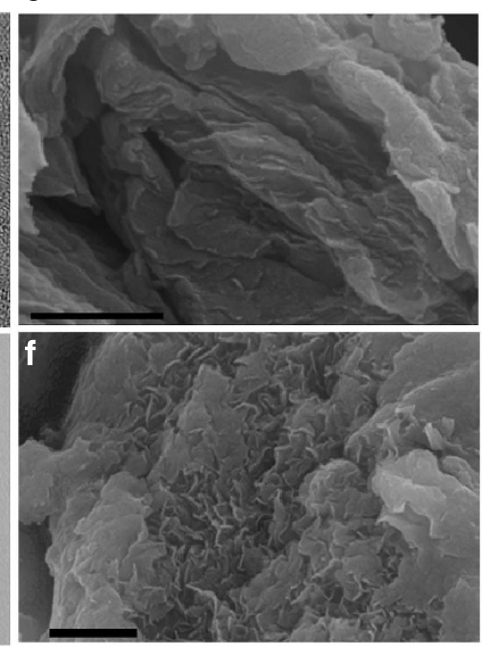

Figure 1 | Morphology and characteristics of the $\mathbf{M n O}_{\mathbf{2}}$ nanosheets and $\mathbf{S} / \mathbf{M n O}_{\mathbf{2}}$ composite. (a) TEM image of $\mathrm{MnO}_{2}$ nanosheets and its corresponding selected area electron diffraction pattern, (b) high-resolution TEM image of $\mathrm{MnO}_{2}$ nanosheets, (c) SEM image of the $\mathrm{MnO}_{2}$ nanosheets, (d) X-ray diffraction pattern of $\mathrm{MnO}_{2}$ nanosheets, (e) TEM and (f) SEM images of the $\mathrm{S} / \mathrm{MnO}_{2}$ nanosheets composite. Scale bars, $50 \mathrm{~nm}(\mathbf{a}) ; 100 \mathrm{~nm}(\mathbf{b}, \mathbf{c}, \mathbf{f}) ; 200 \mathrm{~nm}(\mathbf{e})$. 
sheets of $\mathrm{MnO}_{6}$ octahedra, coordinated both to the $\mathrm{Mn}$ and the $\mathrm{K}$, with some fraction of the former being present as hydroxyl groups $^{37}$. Thermogravimetric analysis (TGA, Supplementary Fig. 1a) reveals that the as-prepared $\mathrm{MnO}_{2}$ nanosheets possess $8 \mathrm{wt} \%$ surface-absorbed water and $3 \mathrm{wt} \%$ water in the interlayers. Melt diffusion at $155^{\circ} \mathrm{C}$ was used to uniformly disperse sulfur onto the surface of the $\mathrm{MnO}_{2}$ nanosheets ${ }^{28-30}$. To maximize contact, the nanosheets were first pre-dispersed by sonication before being mixed with sulfur nanoparticles (see Methods) in a 25:75 weight ratio (Supplementary Fig. 2). The TEM and SEM images in Fig. 1e,f show a homogeneous sulfur coating on the nanosheet surface after melt diffusion, as confirmed by energy dispersive X-ray spectroscopy mapping (Supplementary Fig. 3). The targeted high sulfur loading of $75 \mathrm{wt} \%$ was achieved (TGA analysis of $75 \mathrm{~S} / \mathrm{MnO}_{2}$, Supplementary Fig. 1b).

Electrochemical properties. Electrochemical behaviour evaluated at different current densities for the $75 \mathrm{~S} / \mathrm{MnO}_{2}$ nanocomposite, showed characteristic Li-S voltage profiles (Fig. 2a) ${ }^{12,14}$. The cells exhibit a capacity of $\sim 1,300 \mathrm{~mA} \mathrm{~h}^{-1}$ at C/20 (discharge/charge of full theoretical capacity in $20 \mathrm{~h}$ ). At a 20 -fold higher current density (a C rate), only a modest drop in capacity to $950 \mathrm{mAhg}^{-1}$ was observed, suggestive of highly efficient kinetics. Most notable is the lack of overpotential in the initial charging process even on the first cycle, indicative of a good $\mathrm{Li}_{2} \mathrm{~S}$ interface with the $\mathrm{MnO}_{2}$ nanosheets. Figure $2 \mathrm{~b}$ shows the cycling stability of the cells at different rates. At $\mathrm{C} / 5$, the initial discharge capacity was $1,120 \mathrm{mAhg}^{-1}$, with $1,030 \mathrm{mAhg}^{-1}$ being sustained after more than 200 cycles and representing excellent capacity retention of $0.04 \%$ per cycle. At higher current densities (1C), the $75 \mathrm{~S} / \mathrm{MnO}_{2}$ composite still delivered exceptional reversible capacity of $800 \mathrm{mAhg}^{-1}$ after 200 cycles. This
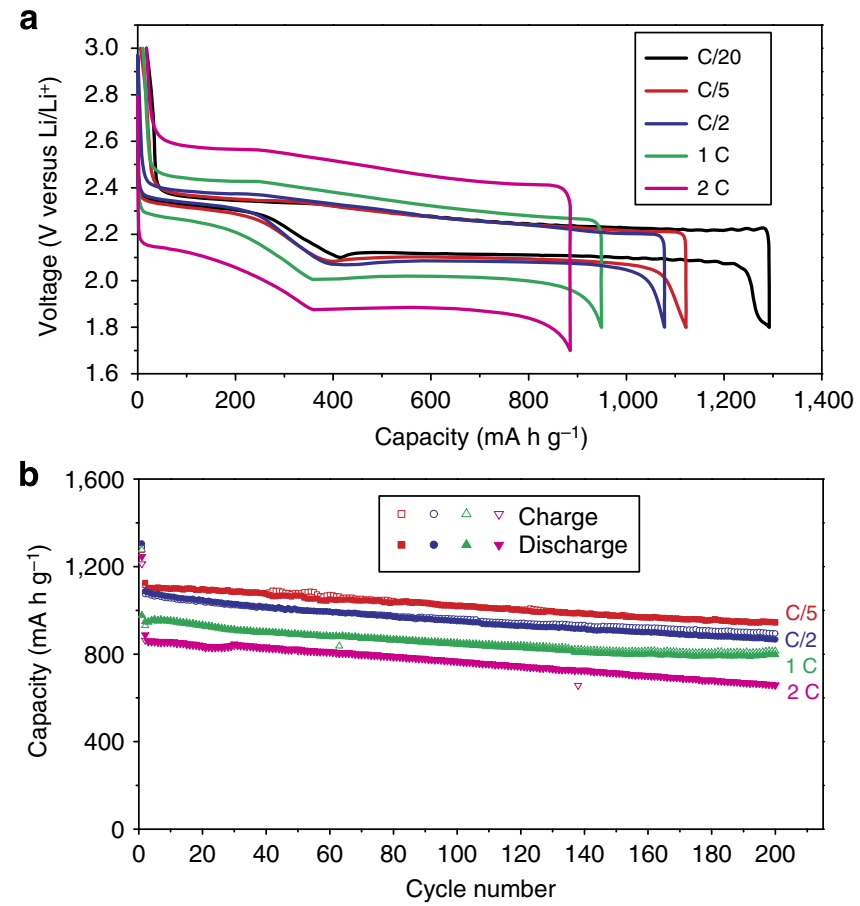

Figure 2 | Electrochemical performance of $\mathbf{S} / \mathbf{M n O}_{2}$. (a) Voltage profiles of $\mathrm{S} / \mathrm{MnO}_{2}$ nanosheets at current densities ranging from $\mathrm{C} / 20$ to $2 \mathrm{C}$. The highlighted circle shows the lack of overpotential. (b) Cycling performance of $\mathrm{S} / \mathrm{MnO}_{2}$ nanosheets at $\mathrm{C} / 5, \mathrm{C} / 2,1 \mathrm{C}$ and $2 \mathrm{C}$ rates. The cells were subjected to an initial slow conditioning cycle at $\mathrm{C} / 20$ to allow complete access of the electrolyte to the active material. indicates that processes such as loss of electrical contact of $\mathrm{Li}_{2} \mathrm{~S}$ or sulfur with the conductive host caused by volume changes or the 'shuttle reaction' caused by the solubilized polysulfides are minimized.

In-situ visual-electrochemical study of $75 \mathrm{~S} / \mathrm{MnO}_{2}$. To further illustrate the excellent properties discussed above, we examined electrochemical behaviour of $75 \mathrm{~S} / \mathrm{MnO}_{2}$ in an optically transparent Li-S cell, exploiting the very strong colour of LiPSs to probe their interaction with the cathode surface. Recent reports have visually demonstrated the binding of LiPSs with metallic metal oxide sulfur hosts such as $\mathrm{Ti}_{4} \mathrm{O}_{7}$ (ref. 32) and spatially localized deposition of $\mathrm{Li}_{2} \mathrm{~S}$ on conductive indium-tin oxide ${ }^{33}$. With $\delta-\mathrm{MnO}_{2}-$ a poor semiconductor-the interaction is based on a very different principle, as detailed in the next section. The cell using $75 \mathrm{~S} / \mathrm{MnO}_{2}$ as the cathode clearly demonstrates the ability of the nanosheet host to control LiPS dissolution. For comparison, results are shown for a S/Ketjen Black (75S/KB) cathode prepared with the same $75 \%$ sulfur loading (Fig. 3). Figure $3 \mathrm{a}$ reveals that the electrolyte in the $75 \mathrm{~S} / \mathrm{KB}$ cell changed from colourless to bright yellow-green on partial discharge of the cell over $4 \mathrm{~h}$. This point corresponds to the 'knee' in the discharge curve at a capacity of $400 \mathrm{~m} \mathrm{Ahg}^{-1}$ (a potential of $2.1 \mathrm{~V}$, see Fig. 2a), where the LiPS concentration is expected to be at a maximum. The characteristic colour of medium chain LiPSs (i.e, $\sim, S_{4}^{2-}$ ) indicates that the polysulfides diffuse out of the cathode and are solubilized in the electrolyte.

At the end of discharge $(12 \mathrm{~h})$, the electrolyte is still yellow, showing LiPSs remain in solution. In contrast, in the $75 \mathrm{~S} / \mathrm{MnO}_{2}$ cell the electrolyte exhibits only a faint yellow colour at $4 \mathrm{~h}$. This provides striking visual evidence of very low LiPS content in the electrolyte and demonstrates effective trapping by the $\mathrm{MnO}_{2}$. On full discharge, the electrolyte is rendered completely colourless, indicating effective conversion to insoluble reduced species, $\mathrm{Li}_{2} \mathrm{~S}_{2}$ and $\mathrm{Li}_{2} \mathrm{~S}$. A test of the polysulfide adsorption by the $\mathrm{MnO}_{2}$ nanosheets was conducted by electrochemical titration to measure the degree of residual LiPS in solution after contact, confirming the strong binding (Supplementary Fig. 4$)^{38}$.

XPS study of the interaction of lithium (poly)sulfides and $\mathrm{MnO}_{2}$ nanosheets. The nature of the interaction of the $\mathrm{MnO}_{2}$

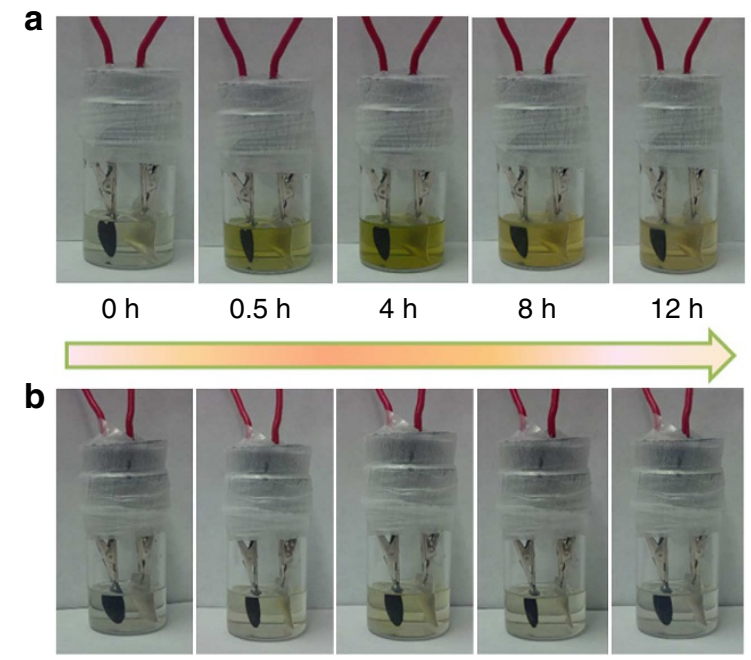

Figure 3 | Visual confirmation of polysulfide entrapment at specific discharge depths. (a) $75 \mathrm{~S} / \mathrm{KB}$ and (b) $75 \mathrm{~S} / \mathrm{MnO}_{2}$ cells. These were both discharged at $\mathrm{C} / 20$ between open circuit potential to $1.8 \mathrm{~V}$ under identical conditions. 
nanosheets with LiPSs was determined from $\mathrm{Mn} 3 p_{3 / 2}$ and S2p X-ray photoelectron spectroscopy (XPS) analysis. Only the peak position of the lower binding energy component of the $\mathrm{S} 2 p_{3 / 2} / 2 p_{1 / 2}$ spin orbit doublet is described in the subsequent discussion following convention. The results are summarized in Figs 4 and 5 .

$\mathrm{Li}_{2} \mathrm{~S}_{4}$ was employed as the representative polysulfide species to probe the system at a partial state of discharge. Its XPS spectrum (Fig. 4a) shows a 1:1 ratio of the two $S 2 p_{3 / 2}$ contributions at 161.7 and $163.1 \mathrm{eV}$, ascribed to the terminal $\left(\mathrm{S}_{\mathrm{T}}^{-1}\right)$ and bridging sulfur $\left(\mathrm{S}_{\mathrm{B}}^{0}\right)$ atoms, respectively. This assignment is in accord with the chain structure of $\mathrm{Li}_{2} \mathrm{~S}_{4}$, where the sulfur atoms at both ends have a formal charge of $(-1)$, while those in the middle bear a formal charge of $(0)^{32,39}$. Figure $4 \mathrm{e}$ displays the XPS Mn $2 \mathrm{p}_{3 / 2}$ spectra of $\delta-\mathrm{MnO}_{2}$, which is mainly composed of $\mathrm{Mn}^{4+}$, with its nearsurface enriched in $\mathrm{Mn}^{3}+$ relative to the bulk ${ }^{40}$. The $\mathrm{MnO}_{2}$ nanosheet spectrum is typical of birnessite ${ }^{41}$, showing a strong Mn $2 p_{3 / 2} \mathrm{Mn}^{4+}$ contribution that appears as a characteristic multiplet with a maximum at $642.5 \mathrm{eV}$, and three satellite peaks at higher binding energies of $643.7,644.8$ and $645.7 \mathrm{eV}$. The ratio of the multiplet peaks is in agreement with calculations ${ }^{41}$. The Mn $2 p_{3 / 2}$ contribution at $641.4 \mathrm{eV}$ corresponds to $\mathrm{Mn}^{3+}$, which makes up $\sim 4.6 \%$ of the $\mathrm{MnO}_{2}$ nanosheets.

To examine the LiPS-Mn interaction, a suspension of vacuumdried $\delta-\mathrm{MnO}_{2}$ in ether was added to a solution of yellow-green $\mathrm{Li}_{2} \mathrm{~S}_{4}$ in dimethoxyethane, resulting in immediate discolouration. XPS data were collected on the recovered solid $\left({ }^{\prime} \mathrm{MnO}_{2}-\mathrm{Li}_{2} \mathrm{~S}_{4}\right.$ '). Its S2p spectrum (Fig. $4 \mathrm{~b}$ ) reveals four sulfur environments. Two are the same terminal and bridging $S$ environments as in $\mathrm{Li}_{2} \mathrm{~S}_{4}$. The new significant contribution between 171 and $165 \mathrm{eV}$ can be fit with two sulfur environments. The $S 2 p_{3 / 2}$ peak at $167.2 \mathrm{eV}$ is in precise accord with the binding energy of thiosulfate ${ }^{42}$, which must arise from a surface redox reaction between $\mathrm{Li}_{2} \mathrm{~S}_{4}$ and $\delta-\mathrm{MnO}_{2}$. This peak is from the 'central' or $\mathrm{S}=\mathrm{O}$ sulfur in thiosulfate $\left(\left[\mathrm{SSO}_{3}\right]^{2-}\right)$, whereas its 'peripheral' sulfur lies at $161.5 \mathrm{eV}$, contributing to the $\mathrm{S}_{\mathrm{T}}^{-1}$ from residual $\mathrm{Li}_{2} \mathrm{~S}_{4}$ (thus accounting for the change in ratio of the $\left(\mathrm{S}_{\mathrm{T}}^{-1}: \mathrm{S}_{\mathrm{B}}^{0}\right) 2 p_{3 / 2}$ peaks from $1: 1$ to $2.4: 1$ ). The S2p XPS spectrum of sodium thiosulfate is provided for reference (Supplementary Fig. $5 \mathrm{a}$ ). The other $S 2 p_{3 / 2}$ peak at $168.2 \mathrm{eV}$ (ascribed to a polythionate complex in the $\mathrm{MnO}_{2}-\mathrm{Li}_{2} \mathrm{~S}_{4}$ material) will be discussed below. Oxidation of $\mathrm{Li}_{2} \mathrm{~S}_{4}$ to thiosulfate is accompanied by a decrease in the Mn oxidation state, as evident in Fig. 4f. The contribution from $\mathrm{Mn}^{3+}$ at $641.4 \mathrm{eV}$ in the Mn $2 p_{3 / 2}$ XPS spectrum significantly increases (from $\sim 5 \%$ to $35 \%$ ) and two additional Mn $2 p_{3 / 2}$ peaks arise at lower energy $(640.4$ and $639.4 \mathrm{eV})$, readily attributable to $\mathrm{Mn}^{2+}$. The overall redox process is summarized in Fig. $4 \mathrm{~g}$. The presence of thiosulfate was also proven by Fourier transform infrared spectroscopy (FTIR). The FTIR spectrum of $\mathrm{Li}_{2} \mathrm{~S}_{4}$ (Supplementary Fig. 6) shows an $\mathrm{S}-\mathrm{S}$ band at $482 \mathrm{~cm}^{-1}$ (ref. 31), whereas $\mathrm{MnO}_{2}$ has a strong antisymmetric $\mathrm{MnO}_{6}$ stretching vibration at $519 \mathrm{~cm}^{-1}$ (ref. 43). The FTIR spectrum of $\mathrm{MnO}_{2}-$ $\mathrm{Li}_{2} \mathrm{~S}_{4}$ exhibits a new peak at $670 \mathrm{~cm}^{-1}$, characteristic of $\mathrm{S}_{2} \mathrm{O}_{3}^{2-}$ (ref. 44), and one very broad peak at $503 \mathrm{~cm}^{-1}$ midway between the contributions expected from $\mathrm{S}-\mathrm{S}$ and $\mathrm{MnO}_{2}$. We attribute this significant shift of both species to a strong interaction at the interface.

To further support the thiosulfate formation mechanism, we investigated the interaction of LiPS with other sulfur hosts-GO (ACS Material, USA) and graphene (ACS Material, single layer). The XPS S2 $p$ spectrum of GO- $\mathrm{Li}_{2} \mathrm{~S}_{4}$ shows the same components as the $\mathrm{MnO}_{2}-\mathrm{Li}_{2} \mathrm{~S}_{4}$ (Fig. 4c), which suggests thiosulfate/ polythionate surface species are formed here as well. The characteristic peaks are reduced in intensity compared with
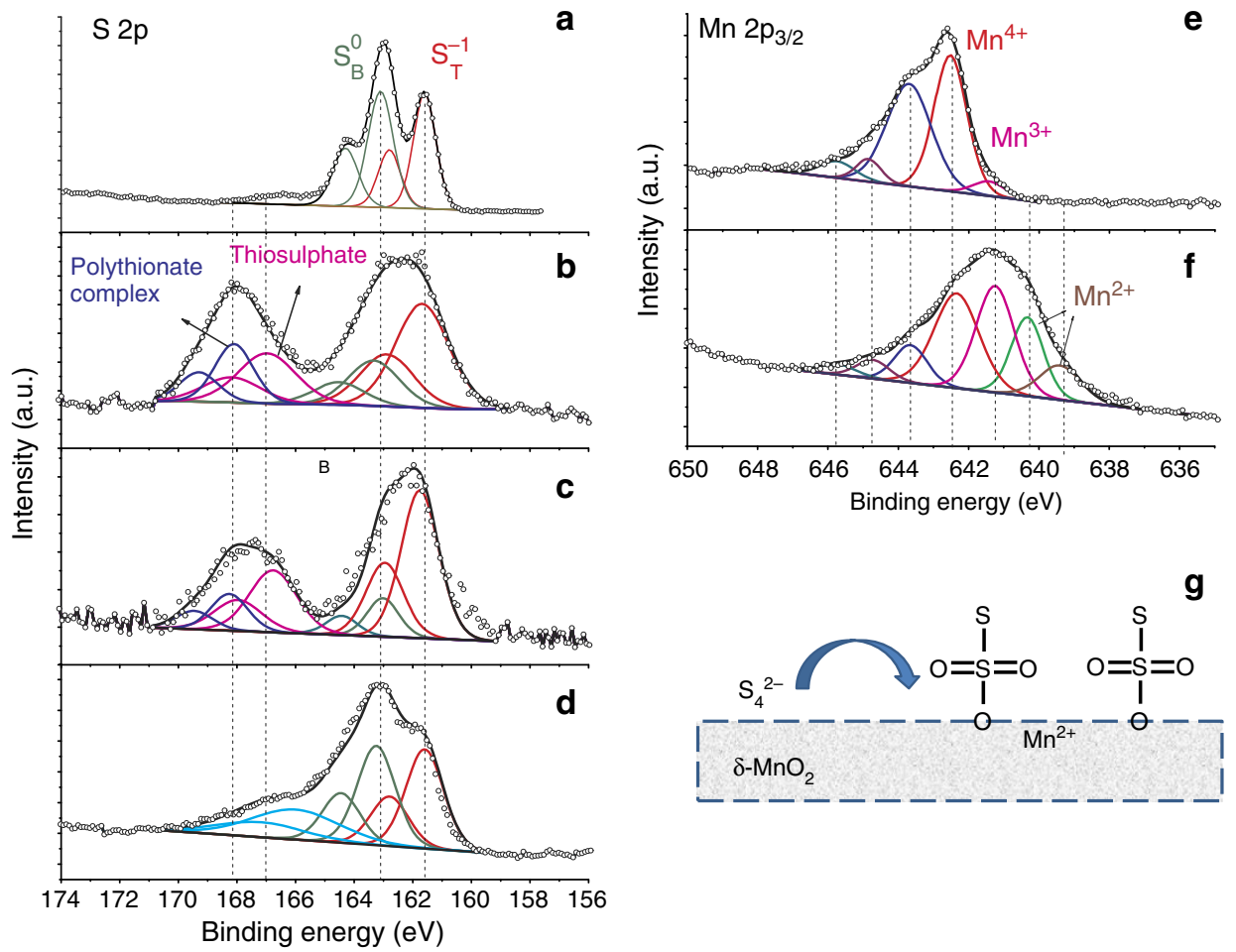

Figure 4 | XPS study of the interaction between sulfur species and $\mathbf{M n O}_{\mathbf{2}}$ nanosheets. S2p core spectra of (a) $\mathrm{Li}_{2} \mathrm{~S}_{4}$ showing the terminal and bridging sulfur atoms in the expected 1:1 ratio; (b) $\mathrm{MnO}_{2}-\mathrm{Li}_{2} \mathrm{~S}_{4}$ and (c) $\mathrm{GO}-\mathrm{Li}_{2} \mathrm{~S}_{4}$ exhibiting the thiosulfate/polythionate active groups and (d) 'graphene'-

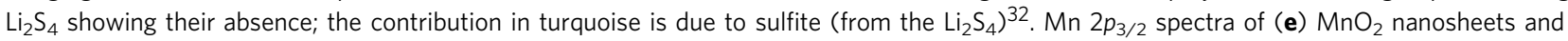
(f) $\mathrm{MnO}_{2}-\mathrm{Li}_{2} \mathrm{~S}_{4}$. (g) Schematic showing the oxidation of initially formed polysulphide by $\delta-\mathrm{MnO}_{2}$ to form thiosulfate on the surface, concomitant with the reduction of $\mathrm{Mn}^{4+}$ to $\mathrm{Mn}^{2+}$. 


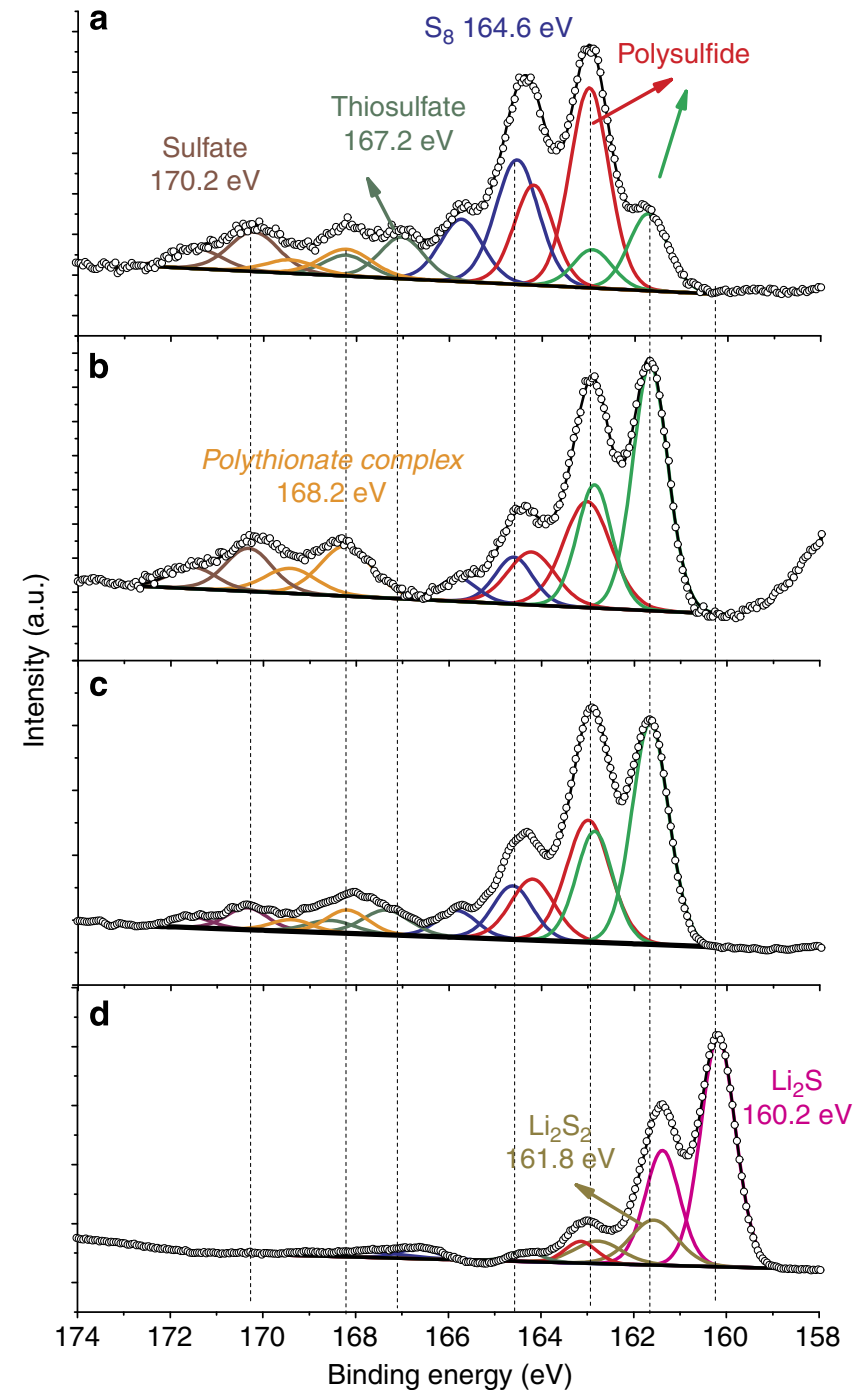

Figure 5 | Ex-situ XPS of $\mathbf{S} / \mathrm{MnO}_{2}$ nanosheets electrodes after discharge to specific states. (a) Discharged to $2.15 \mathrm{~V}$, (b) discharged to $2.15 \mathrm{~V}$ and then aged in the cell for $20 \mathrm{~h}$, (c) discharged to $800 \mathrm{~mA} \mathrm{~h}^{-1}$ (the middle of the second plateau) and (d) discharged to $1.8 \mathrm{~V}$. All cells were galvanostatically discharged at $\mathrm{C} / 20$ with $1 \mathrm{M} \mathrm{LiClO}_{4}$ in DOL/DME (1:1 vol) as the electrolyte. The trace of sulfate at $170.2 \mathrm{eV}$ is due to momentary air exposure during the XPS sample loading process.

$\delta-\mathrm{MnO}_{2}$, as expected. The XPS C 1 s comparison of the GO and $\mathrm{GO}-\mathrm{Li}_{2} \mathrm{~S}_{4}$ confirms the chemical interaction of $\mathrm{LiPS}$ in $\mathrm{GO}-\mathrm{Li}_{2} \mathrm{~S}_{4}$, showing that $20 \%$ of the $\mathrm{C}-\mathrm{O}(\mathrm{H})$ bonds were reduced to $\mathrm{C}-\mathrm{C}$ (see Supplementary Fig. 7). Regarding the S2p spectrum of graphene$\mathrm{Li}_{2} \mathrm{~S}_{4}$, it shows two contributions at 161.7 and $163.1 \mathrm{eV}$, identical to that of $\mathrm{Li}_{2} \mathrm{~S}_{4}$ itself (Fig. $4 \mathrm{~d}$ ). This suggests almost no interaction between graphene and polysulfides. The absence of thiosulfate in graphene- $\mathrm{Li}_{2} \mathrm{~S}_{4}$ implies that the thiosulfate oxygen originates from surface oxy-groups on $\mathrm{GO}$; for $\mathrm{MnO}_{2}$, these arise from the $\mathrm{OH}$ groups that replace some of the $\mathrm{O}^{2-}$ in the birnessite structure for charge balance. This additional XPS analysis and insight into thiosulfate formation can explain the origin of the excellent cyclability of the $\mathrm{MnO}_{2}$ nanosheets and that of $\mathrm{GO}$ materials ${ }^{25,26}$, as discussed in detail below.

XPS analysis was further conducted on $75 \mathrm{~S} / \mathrm{MnO}_{2}$ nanosheet electrodes extracted from cells at different discharge states (Fig. 5ad). When the cell was discharged to $2.15 \mathrm{~V}$, the presence of longchain polysulfides is evidenced by strong $\mathrm{S} 2 p_{3 / 2}$ contributions at
$161.7\left(\mathrm{~S}_{\mathrm{T}}^{-1}\right)$ and $162.9 \mathrm{eV}\left(\mathrm{S}_{\mathrm{B}}^{-2}\right)(\text { Fig. } 5 \mathrm{a})^{32,39}$, with their 1:2 ratio suggesting a chain length approximately equal to $\mathrm{Li}_{2} \mathrm{~S}_{6}$ owing to the 2:4 ratio of terminal/bridging sulfur in this LiPS. Elemental sulfur was also detected at this and other intermediate states of discharge, consistent with incomplete reaction and/or the disproportionation of metastable polysulfides such as $\mathrm{Li}_{2} \mathrm{~S}_{8}$ to form $\mathrm{Li}_{2} \mathrm{~S}_{6}$ and sulfur as previously reported ${ }^{45}$. S2 $p$ peaks between 166 and $170 \mathrm{eV}$ correspond to two sulfur environments: one at $167.2 \mathrm{eV}$ (thiosulfate) and another at $168.2 \mathrm{eV}$, which is assigned to a polythionate complex as discussed above. These are the same as observed in the S2p spectrum of $\mathrm{MnO}_{2}-\mathrm{Li}_{2} \mathrm{~S}_{4}$ in Fig. $4 \mathrm{~b}$. The thiosulfate peak vanishes when the electrode is aged in the coin cell for $20 \mathrm{~h}$ after discharge to $2.15 \mathrm{~V}$; only the peak due to the polythionate complex remains in this region. Thus, transformation of thiosulfate to the polythionate complex is accompanied by the conversion of longer-chain polysulfides to shorter-chain polysulfides ( $\sim \mathrm{Li}_{2} \mathrm{~S}_{3}$ based on the 2:1 ratio of the terminal:bridging sulfur; see Supplementary Fig. 8, for concentrations of each specific component). Exactly the same reaction is also observed between sodium thiosulfate and polysulfides $\left(\mathrm{Li}_{2} \mathrm{~S}_{4}\right)$, as shown in Supplementary Fig. 5b.

We conclude that S-S from longer-chain polysulfide species reacts with thiosulfate to yield the polythionate complex and shorter polysulfides. Prolonged contact time results in more complete conversion. XPS analysis of the electrode collected at the middle of the second plateau (Fig. $5 \mathrm{c} ; 800 \mathrm{mAhg}^{-1}$ ) shows that the sulfur environments are the same as the electrode discharged to $2.15 \mathrm{~V}$. Their different relative intensities represent the further consumption of longer-chain polysulfides accompanied by the formation of shorter-chain polysulfides. After the electrode was fully discharged to $1.8 \mathrm{~V}$, this process is essentially complete (Fig. 5d). The contribution from thiosulfate and the polythionate complex is small, whereas a strong contribution from $\mathrm{Li}_{2} \mathrm{~S}\left(\mathrm{~S} 2 p_{3 / 2}\right.$ at $160.2 \mathrm{eV})$ along with $\sim 20 \% \mathrm{Li}_{2} \mathrm{~S}_{2}(161.7 \mathrm{eV})$ indicates almost full reduction of sulfur in the electrode. The minority contribution from $\mathrm{Li}_{2} \mathrm{~S}_{2}$ was assigned based on its very similar binding energy as that of $\mathrm{Na}_{2} \mathrm{~S}_{2}\left(161.8 \mathrm{eV}^{32}\right.$, and see Supplementary Fig. 9). On charge, the XPS spectrum (Supplementary Fig. 10) is similar to Fig. 5a, revealing the re-appearance of the polythionate complex along with polysulfides and sulfur, and indicating that the process is reversible.

\section{Discussion}

We propose that the insoluble $\mathrm{S}_{2} \mathrm{O}_{3}^{2-}$ that forms on the surface serves as an internal mediator to anchor long-chain polysulfides from solution and trigger conversion to lower polysulfides via the reaction shown below (equation (1)):

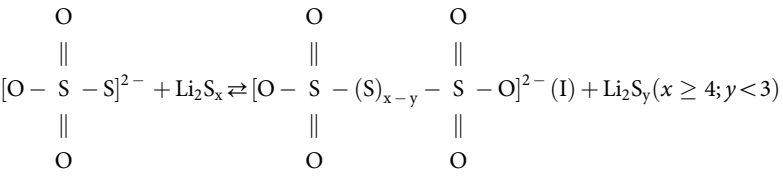

In this mechanism, the polysulfide catenates to the thiosulfate by insertion in the $\mathrm{S}-\mathrm{S}$ single bond to create the polythionate complex (I) and a lower polysulfide (that is, $\mathrm{Li}_{2} \mathrm{~S}_{2}$ or $\mathrm{Li}_{2} \mathrm{~S}$ ) by an internal disproportionation reaction. This can be explained by the attack of the highly nucleophilic thiosulfate on the bridging $\mathrm{S}(0)$ in the polysulfides followed by associative nucleophilic substitution. Sulfur is well known to undergo catenation reactions, such as recently proven for the reaction of sulfur with $\mathrm{Li}_{3} \mathrm{PS}_{4}$ to form polysulfidophosphates, $\mathrm{Li}_{3} \mathrm{PS}_{4+\mathrm{n}}$ (ref. 46). Elemental sulfur is also susceptible to nucleophilic attack by $\mathrm{HS}^{-}$or $\mathrm{SO}_{3}^{2-}$ in aqueous solution, resulting in the formation of chains of polysulfides or polythionate complexes, respectively. This is known as the "Wackenroder reaction'47. The polythionate 
complex could also be formed with only one $-\mathrm{SO}_{3}$ group (equation (2)):

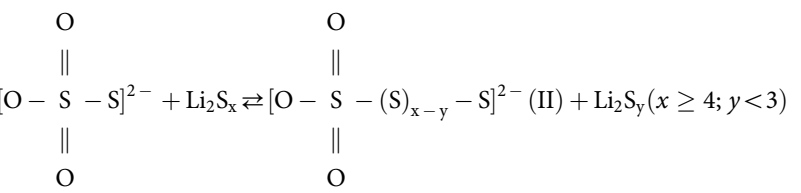

However, the bi-polythionate complex (I) is preferred due to its known stability (albeit in aqueous media) ${ }^{47}$. Based on the above model, the electrochemistry of the Li-S system can be explained as follows: (1) initial formation of $\operatorname{Li}_{2} S_{n}(4 \leq n \leq 8)$ at the start of discharge gives rise to reaction with $\mathrm{MnO}_{2}$, producing thiosulfate at the surface; (2) further reduction produces more polysulfides $(4<n<8)$ that are immediately catenated to form an intermediate polythionate complex and shorter-chain polysulfides $(n<3)$. The polythionate complex is expected to be poorly soluble, curtailing the polysulfide shuttle. The process occurs progressively on discharge until full conversion to $\mathrm{Li}_{2} \mathrm{~S}_{2} /$ $\mathrm{Li}_{2} \mathrm{~S}$ is achieved. Deposition of lithium sulfide presumably overlays the signature of polythionate complex and thiosulfate, as XPS only probes $<10 \mathrm{~nm}$ of the surface.

To evaluate the efficiency of the thiosulfate mediator, longterm cycling was performed at $\mathrm{C} / 5, \mathrm{C} / 2$ and $2 \mathrm{C}$ rates. The two former current densities are suitable for practical applications, while the latter is a benchmark for power utilization. For the C/5 cell (Fig. 6a), galvanostatic cycling for over half a year still results in a capacity of $380 \mathrm{~mA} \mathrm{~h} \mathrm{~g}^{-1}$ after 1,200 cycles. Similarly good performance was achieved at C/2 (Fig. 6b) over 1,500 cycles. After
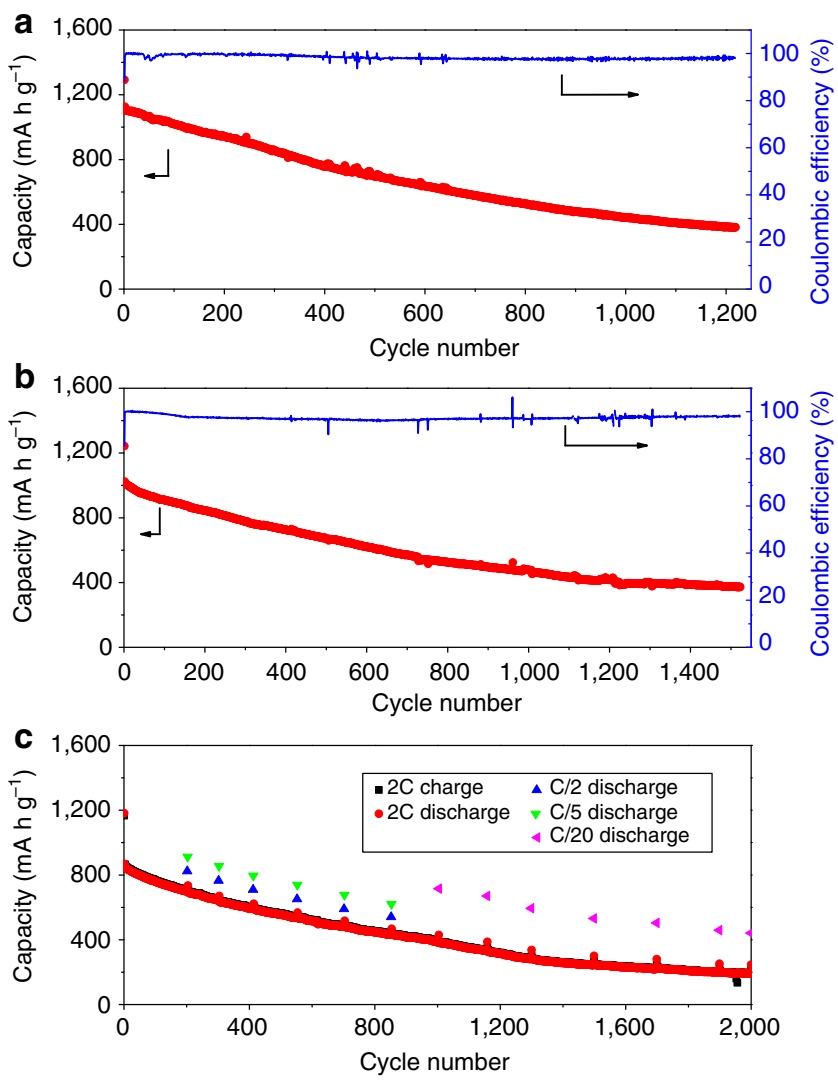

Figure 6 | Long-term cycling of $\mathbf{7 5 S} / \mathrm{MnO}_{2}$ at variable current densities. Capacity and the Coulombic efficiency at (a) C/5 over 1,200 cycles, (b) $\mathrm{C} / 2$ over 1,500 cycles, (c) $2 \mathrm{C}$ with periodic slow rate for over 2,000 cycles. The capacities of the $\mathrm{C} / 2$ and $\mathrm{C} / 5$ cells are quite similar to those shown in Fig. 2, demonstrating the reproducibility of the electrochemistry.
2,000 cycles at $2 \mathrm{C}, 245 \mathrm{mAhg}^{-1}$ useable capacity was still available with good Coulombic efficiency $(>98.5 \%)$ and a very low decay rate of $0.036 \%$ per cycle. The rate was periodically changed to investigate the specific capacity that can be delivered at lower C-rates. After 1,000 cycles at $2 \mathrm{C}$ a discharge capacity of $715 \mathrm{~mA} \mathrm{~h}^{-1}$ was obtained at $\mathrm{C} / 20$, and even after 2,000 cycles at $2 \mathrm{C}$ a reversible discharge capacity of $460 \mathrm{mAhg}^{-1}$ was achieved at $\mathrm{C} / 20$ (Fig. 6c). The electrochemical robustness extends to cycling at very high $\mathrm{C}$-rates. On switching the C-rate from $3 \mathrm{C}$ to $\mathrm{C} / 5$, the discharge capacity $\left(985 \mathrm{mAhg}^{-1}\right)$ was $96.3 \%$ of the original capacity (Supplementary Fig. 11). At the high rate of $4 \mathrm{C}$, a stable capacity of $700 \mathrm{~mA} \mathrm{~h}^{-1}$ was achieved and most of the original capacity was recovered on switching back to a C-rate. Moreover, the overall morphology and structure of the electrode after 1,000 cycles is very similar to that of the original material, as shown in Supplementary Fig. 12. This suggests that the $\mathrm{MnO}_{2}$ nanosheet host acts to spatially locate and control both $\mathrm{Li}_{2} \mathrm{~S} / \mathrm{Li}_{2} \mathrm{~S}_{2}$ and sulfur deposition by providing an active interface via the thiosulfate intermediate and demonstrates the excellent stability of this cathode material.

In summary, by the in-situ generation of thiosulfate surface species, which react to form an active complex on the surface of $\mathrm{MnO}_{2}$ nanosheets, we demonstrate that it is possible to cycle a $\mathrm{Li}-$ $\mathrm{S}$ cell with a capacity decay as low as $0.036 \%$ per cycle over 2,000 cycles, using a classic low viscosity dioxolane (DOL)-dimethyl ether (DME) electrolyte and polyvinylidene fluoride binder. We propose that a new, unique mechanism is responsible, whereby an active polythionate complex serves as an anchor and transfer mediator to inhibit active mass (polysulfide) dissolution into the electrolyte and control the deposition of $\mathrm{Li}_{2} \mathrm{~S}_{2}$ or $\mathrm{Li}_{2} \mathrm{~S}$. The resultant cells deliver high rechargeable capacity at practical current densities and high sulfur loading. We furthermore note that the thiosulfate mediator is not restricted to support on $\mathrm{MnO}_{2}$ nanosheets, but is broadly applicable to other support materials and may be also responsible-in whole or in part-for the excellent cycling behaviour observed for GO composites. Unlike previous strategies to trap polysulfides by physical barriers or simple surface interactions, this chemistry is quite efficient. The discovery and understanding of a transfer mediator, which binds polysulfides and promotes stable redox activity, addresses one of the important challenges that face this chemistry. Along with future anticipated improvements in electrolytes and the lithiumnegative electrode, this brings the Li-S battery a step closer to practical realization.

\section{Methods}

Preparation of the $\mathbf{M n O}_{\mathbf{2}}$ nanosheets. The layered $\mathrm{MnO}_{2}$ nanosheets were synthesized by a one-step facile method using GO as template. Briefly, $20 \mathrm{mg}$ of single-layer GO (ACS Materials) were dispersed in $100 \mathrm{ml}$ deionized (DI) water by sonication. A well-mixed solution of $10 \mathrm{ml} \mathrm{DI}$ water and $160 \mathrm{mg}$ of $\mathrm{KMnO}_{4}$ (Sigma-Aldrich) was added into the GO suspension and stirred at room temperature for $30 \mathrm{~min}$. The mixture was transferred into a thermostatic oven at $80^{\circ} \mathrm{C}$ for $24 \mathrm{~h}$. The resulting material was washed with DI water.

Preparation of the $\mathbf{7 5 S} / \mathbf{M n O}_{\mathbf{2}}$ composite. For sulfur loading onto the $\mathrm{MnO}_{2}$ nanosheets, the nano-sized sulfur was first synthesized by reacting $255 \mathrm{mg} \mathrm{Na} \mathrm{S}_{2} \mathrm{O}_{3}$ (Sigma-Aldrich) with $278 \mu \mathrm{l}$ concentrated $\mathrm{HCl}$ and $17 \mathrm{mg}$ polyvinylpyrrolidone (Sigma-Aldrich) in $85 \mathrm{ml}$ DI water. The $\mathrm{MnO}_{2}$ nanosheets and nano-sized sulfur were dispersed in $40 \mathrm{ml}$ DI water separately by sonication before being mixed to obtain a homogenous suspension. The suspension was filtered and then dried at $60^{\circ} \mathrm{C}$. The $75 \mathrm{~S} / \mathrm{MnO}_{2}$ nanosheet composite was obtained by heating the mixture at $155^{\circ} \mathrm{C}$ overnight.

Synthesis of $\mathbf{L i}_{\mathbf{2}} \mathbf{S}_{\mathbf{4}}$. Sulfur (Sigma-Aldrich) and Super-Hydride Solution (Aldrich $1.0 \mathrm{M}$ lithium triethylborohydride in tetrahydrofuran) were mixed together in a 2.75:1 molar ratio until the sulfur was fully dissolved. The resulting solution was dried under vacuum, resulting in precipitation of a yellow powder. A final wash with toluene was conducted, followed by centrifugation to separate the powder from the supernatant to isolate the $\mathrm{Li}_{2} \mathrm{~S}_{4}$ powder. 
Preparation of $\mathbf{M n O}_{\mathbf{2}}-\mathrm{Li}_{\mathbf{2}} \mathbf{S}_{\mathbf{4}}$. The $\mathrm{MnO}_{2}$ nanosheets $(87 \mathrm{mg} ; 1 \mathrm{mmol}$ ) were dried at $90^{\circ} \mathrm{C}$ under vacuum overnight and dispersed in $10 \mathrm{ml}$ DME solution by sonication in a sealed vial. The mixture was transferred to a glovebox and combined with $10 \mathrm{ml}$ of $0.1 \mathrm{M} \mathrm{Li}_{2} \mathrm{~S}_{4}$ in DME. The mixture was stirred for $2 \mathrm{~h}$ and the product was centrifuged and dried under vacuum overnight. $\mathrm{GO}-\mathrm{Li}_{2} \mathrm{~S}_{4}$ and graphene-Li2S4 samples were prepared by the same procedure.

Preparation of $\mathbf{M n O}_{\mathbf{2}}-\mathrm{Li}_{2} \mathbf{S}$. $75 \mathrm{~S} / \mathrm{MnO}_{2}$ was mixed with DMF and then cast as a slurry onto a carbon paper current collector. A 2325 coin cell was discharged to $1.8 \mathrm{~V}$ at a C/20 rate, using $1 \mathrm{M} \mathrm{LiClO}_{4}$ in a 1:1 v/v ratio of DOL:DME as the electrolyte with lithium foil as the anode. The cathode was then removed from the coin cell in a glovebox and rinsed with acetonitrile three times before being dried.

Electrochemical measurements. Cathodes were prepared by casting the DMF slurry containing $75 \mathrm{~S} / \mathrm{MnO}_{2}$ nanosheets, $15 \mathrm{wt} \%$ Super P carbon and $10 \mathrm{wt} \%$ polyvinylidene fluoride onto a carbon paper current collector. Electrochemical studies were carried out using an Arbin cycler in galvanostatic mode, employing electrodes with an average sulfur loading between 0.7 and $1.0 \mathrm{mg} \mathrm{cm}^{-2}$ in 2325 coin cells with lithium foil as the anode and Celgard 3501 separator sheets. Cells were operated in a voltage window of $1.8-3.0 \mathrm{~V}$, except for high-rate studies that were conducted between 1.7 and $3.0 \mathrm{~V}$ ( $2 \mathrm{C}$ and $3 \mathrm{C}$ rates), and between 1.6 and 3.0 V (4C rate), in an electrolyte comprising $1 \mathrm{M}$ LiTFSI in a 1:1 volume of DME:DOL and $2 \mathrm{wt} \% \mathrm{LiNO}_{3}$. Specific capacity values were calculated with respect to the mass of sulfur. Electrodes for XPS analysis were prepared by discharging coin cells at $\mathrm{C} / 20$ in $1 \mathrm{M} \mathrm{LiClO}_{4}$ (to avoid sulfur contributions from LiFTSI) in a $1: 1 \mathrm{v} / \mathrm{v}$ ratio of DOL and DME.

Characterization. SEM studies were carried out on a Zeiss Ultra field emission SEM instrument and TEM was performed on a Jeol 2010F TEM/STEM operating at $200 \mathrm{KeV}$. TGA was used to determine the sulfur content of the material, on a TA Instruments SDT Q600 employing a heating rate of $10^{\circ} \mathrm{C} / \mathrm{min}$ from room temperature to $500^{\circ} \mathrm{C}$ under an air flow. FTIR analysis was performed on a Bruker Tensor 37 spectrometer. For XPS, the samples were sealed in a vial before being quickly transferred to the chamber of a ultra-high vacuum Imaging XPS Microprobe system for analysis (Thermo VG Scientific ESCALab 250). All spectra were fitted with Gaussian-Lorentzian functions and a Shirley-type background using CasaXPS software. S2 $p$ peaks were fit using two equal full-width half maximum S2p doublets with 2:1 area ratios and splittings of $1.2 \mathrm{eV}$. The binding energy values were all calibrated using the $\mathrm{C} 1 \mathrm{~s}$ peak at $285.0 \mathrm{eV}$.

\section{References}

1. Choi, N. S. et al. Challenges facing lithium batteries and electrical double-layer capacitors. Angew. Chem. Int. Ed. 51, 9994-10024 (2012).

2. Yoo, H. D., Markevich, E., Salitra, G., Sharon, D. \& Aurbach, D. On the challenge of developing advanced technologies for electrochemical energy storage. Mater. Today 17, 110-121 (2014).

3. Manthiram, A. Materials challenges and opportunities of lithium ion batteries. J. Phys. Chem. Lett. 2, 176-184 (2011).

4. Ellis, B., Lee, K. T. \& Nazar, L. F. Positive electrode materials for Li-ion and Li-batteries. Chem. Mater. 22, 691-714 (2010).

5. Bruce, P. G., Freunberger, S. A., Hardwick, L. J. \& Tarascon, J. M. Li- $\mathrm{O}_{2}$ and Li-S batteries with high energy storage. Nat. Mater. 11, 19-29 (2012).

6. Yin, Y. X., Xin, S., Guo, Y. G. \& Wan, L. J. Lithium-sulphur batteries: electrochemistry, materials, and prospects. Angew. Chem. Int. Ed. 52, 2-18 (2013).

7. Evers, S. \& Nazar, L. F. New approaches for high energy density lithium-sulfur batteries. Acc. Chem. Res. 46, 1135-1143 (2013).

8. Peled, E., Gorenshtein, A., Segal, M. S. \& Sternberg, Y. Rechargeable lithium sulfur battery. J. Power Sources 26, 269-271 (1989).

9. Yang, Y., Zheng, G. Y. \& Cui, Y. Nanostructured sulphur cathodes. Chem. Soc. Rev. 42, 3018-3032 (2013).

10. Mikhaylik, Y. V. \& Akridge, J. R. Polysulfide shuttle study in the Li/S battery system. J. Electrochem. Soc. 151, A1969-A1976 (2004).

11. Ji, X. L., Lee, K. T. \& Nazar, L. F. A highly ordered nanostructured carbonsulphur cathode for lithium-sulphur batteries. Nat. Mater. 8, 500-506 (2009).

12. Schuster, J. et al. Spherical ordered mesoporous carbon nanoparticles with high porosity for lithium-sulphur batteries. Angew. Chem. Int. Ed. 51, 3591-3595 (2012).

13. He, G., Ji, X. L. \& Nazar, F. L. High 'C' rate Li-S cathodes: sulphur imbibed bimodal porous carbons. Energy Environ. Sci. 4, 2878-2883 (2011).

14. Liang, C. D., Dudney, N. J. \& Howe, J. Y. Hierarchically structured sulphur/ carbon nanocomposite material for high-energy lithium battery. Chem. Mater. 21, 4724-4730 (2009).

15. He, G. et al. Tailoring porosity in carbon nanospheres for lithium sulphur battery cathodes. ACS Nano 7, 10920-10930 (2013).

16. Jayaprakash, N., Shen, J., Moganty, S. S., Corona, A. \& Archer, L. A. Porous hollow carbon@sulphur composites for high-power lithium-sulphur batteries. Angew. Chem. Int. Ed. 50, 5904-5908 (2011).
17. Zhang, B., Qin, X., Li, G. R. \& Gao, X. P. Enhancement of long stability of sulphur cathode by encapsulating sulphur into micropores of carbon spheres. Energy Environ. Sci. 3, 1531-1537 (2010).

18. Elazari, R., Salitra, G., Garsuch, A., Panchenko, A. \& Aurbach, D. Sulphur impregnated activated carbon fiber cloth as a binder-free cathode for rechargeable Li-S batteries. Adv. Mater. 23, 5641-5644 (2011).

19. Zheng, G., Yang, Y., Cha, J. J., Hong, S. S. \& Cui, Y. Hollow carbon nanofiber encapsulated sulphur cathodes for high specific capacity rechargeable lithium batteries. Nano Lett. 11, 4462-4467 (2011).

20. Guo, J., Xu, Y. \& Wang, C. Sulphur-impregnated disordered carbon nanotubes cathode for lithium-sulphur batteries. Nano Lett. 11, 4288-4294 (2011).

21. Zhou, W. D., Yu, Y. C., Chen, H., DiSalvo, F. J. \& Abruña, H. D. Yolk-shell structure of polyaniline coated sulphur for lithium-sulphur batteries. J. Am. Chem. Soc. 135, 16736-16743 (2013).

22. Fu, Y. Z. \& Manthiram, A. Orthorhombic bipyramidal sulphur coated with polypyrrole nanolayers as a cathode material for lithium-sulphur batteries. J. Phys. Chem. C 116, 8910-8915 (2012).

23. Liang, X. et al. A nano-structured and highly ordered polypyrrole-sulphur cathode for lithium-sulphur batteries. J. Power Sources 196, 6951-6955 (2011).

24. Yang, Y. et al. Improving the performance of lithium-sulphur batteries by conductive polymer coating. ACS Nano 5, 9187-9193 (2011).

25. Ji, L. et al. Graphene oxide as a sulphur immobilizer in high performance lithium/sulphur cells. J. Am. Chem. Soc. 133, 18522-18525 (2011).

26. Song, M. K., Zhang, Y. G. \& Cairns, E. J. A long-life, high-rate lithium/sulphur cell: a multifaceted approach to enhancing cell performance. Nano Lett. 13, 5891-5899 (2013).

27. Zhou, G. M. et al. Fibrous hybrid of graphene and sulphur nanocrystals for high-performance lithium-sulphur batteries. ACS Nano 7, 5367-5375 (2013).

28. Qiu, Y. C. et al. High-rate, ultralong cycle-life lithium/sulfur batteries enabled by nitrogen-doped graphene. Nano Lett. 14, 4821-4827 (2014).

29. Seh, Z. W. et al. Sulphur $\mathrm{TiO}_{2}$ yolk-shell nanoarchitecture with internal void space for long-cycle lithium-sulphur batteries. Nat. Commun. 4, 1331 (2013).

30. Ji, X., Evers, S., Black, R. \& Nazar, L. F. Stabilizing lithium-sulphur cathodes using polysulphide reservoirs. Nat. Commun. 2, 325 (2011).

31. Evers, S., Yim, T. \& Nazar, L. F. Understanding the nature of absorption/ adsorption in nanoporous polysulfide sorbents for the Li-S battery. J. Phys. Chem. C. 116, 19653-19658 (2012).

32. Pang, Q., Kundu, D., Cuisinier, M. \& Nazar, L. Surface-enhanced redox chemistry of polysulphides on a metallic and polar host for lithium-sulphur batteries. Nat. Commun. 5, 4759 (2014).

33. Yao, H. B. et al. Improving lithium-sulphur batteries through spatial control of sulphur species deposition on a hybrid electrode surface. Nat. Commun. 5, 3943 (2014).

34. Meini, S., Elazari, R., Rosenman, A. \& Aurbach, D. The use of redox mediators for enhancing utilization of $\mathrm{Li}_{2} \mathrm{~S}$ cathodes for advanced Li-S battery systems. J. Phys. Chem. Lett. 5, 915-918 (2014).

35. Lin, Z., Liu, Z. C., Fu, W. J., Dudney, N. J. \& Liang, C. D. Phosphorous pentasulfide as a novel additive for high-performance lithium-sulfur batteries. Adv. Funct. Mater. 23, 1064-1068 (2013).

36. Zhao, G. X. et al. synthesizing $\mathrm{MnO}_{2}$ nanosheets from graphene oxide templates for high performance pseudosupercapacitors. Chem. Sci. 3, 433-437 (2012).

37. Ma, R. Z., Bando, Y., Zhang, L. Q. \& Sasaki, T. Layered $\mathrm{MnO}_{2}$ nanobelts: hydrothermal synthesis and electrochemical measurements. Adv. Mater. 16, 918-922 (2004).

38. Nazar, L. et al. Rational design of sulphur host materials for Li-S batteries: correlating lithium polysulphide adsorptivity and self-discharge capacity loss. Chem. Commun. doi: 10.1039/C4CC08980D (2014)

39. Kartio, I. J., Basilio, C. I. \& Yoon, R. H. An XPS study of sphalerite activation by copper. Langmuir 14, 5274-5278 (1998).

40. Najdoski, M., Koleva, V., Demiri, S. \& Stojkovikj, S. A simple chemical method for deposition of electrochromic potassium manganese oxide hydrate thin films. Mater. Res. Bull. 47, 2239-2244 (2012).

41. Nesbitt, H. W. \& Banerjee, D. Interpretation of XPS Mn(2p) spectra of Mn oxyhydroxides and constraints on the mechanism of $\mathrm{MnO}_{2}$ precipitation. Amer. Miner. 83, 305-315 (1998)

42. Lindberg, B. J. et al. Molecular spectroscopy by means of ESCA II. Sulphur compounds. Correlation of electron binding energy with structure. Phys. Scr. 1, 286-298 (1970).

43. Julien, C. M., Massot, M. \& Poinsignon, C. Lattice vibrations of manganese oxides Part I. Periodic structures. Spectrochim. Acta A 60, 689-700 (2004).

44. Miller, F. A. \& Wilkins, C. H. Infrared spectra and characteristic frequencies of inorganic ions. Anal. Chem. 24, 1253-1294 (1952).

45. Cuisinier, M. et al. Sulphur speciation in Li-S batteries determined by operando X-ray absorption spectroscopy. J. Phys. Chem. Lett. 4, 3227-3232 (2013). 
46. Lin, Z., Liu, Z. C., Fu, W. J., Dudney, N. J. \& Liang, C. D. Lithium polysulfidophosphates: a family of lithium-conducting sulphur-rich compounds for lithium-sulphur batteries. Angew. Chem. Int. Ed. 125, 1-5 (2013).

47. Holleman-Wiberg: Inorganic Chemistry (eds Wiberg, N.) 514 (Academic Press, 2001).

\section{Acknowledgements}

The research was supported by the BASF International Scientific Network for Electrochemistry and Batteries. We thank Dr Carmen Andrei, MacMaster University, and the Canadian Centre for Electron Microscopy for help with acquisition of the TEM images, and NSERC for platform funding through a Discovery Grant to LFN.

\section{Author contributions}

X.L. and L.F.N. designed this study. X.L. prepared materials and carried out the electrochemical experiments. X.L., C.H. and Q.P. carried out of the XPS investigation.
X.L. carried out data processing and prepared figures. X.L. and L.F.N. wrote the manuscript. T.W. first suggested the proposed mechanism and all of the authors contributed to the scientific discussion.

\section{Additional information}

Supplementary Information accompanies this paper at http://www.nature.com/ naturecommunications

Competing financial interests: The authors declare no competing financial interests

Reprints and permission information is available online at http://npg.nature.com/ reprintsandpermissions/

How to cite this article: Liang, X. et al. A highly efficient polysulfide mediator for lithium-sulfur batteries. Nat. Commun. 6:5682 doi: 10.1038/ncomms6682 (2015) 